\title{
Factors Associated with Strain in Informal Caregivers of Stroke Patients
}

\author{
Jen-Wen Hung, MD; Yu-Ching Huang¹, RN; Jin-Hua Chen², PhD; Li-Na Liao ${ }^{3}$, MSc; \\ Chun-Ju Lin, MD; Chia-Ying Chuo, PT; Ku-Chou Chang', MD
}

Background: Stroke is one of the most prevalent causes of adult disability and handicap. Informal caregivers play an important role in poststroke care. However, informal caregivers may experience strain, which threatens the recovery of stroke subjects. This study aimed to describe changes in strain experienced by informal caregivers from 3 to 6 months after the stroke, and identify the predicting factors.

Methods: We recruited pairs of inpatients with ischemic stroke and informal caregivers from a tertiary referral hospital and interviewed them at 3 and 6 months after the stroke. Caregiver strain was evaluated using the Caregiver Strain Index (CSI), with a CSI $\geqq 7$ indicating considerable caregiver strain. Various factors associated with caregiver strain were analyzed using generalized estimating equations.

Results: Eighty-nine stroke patients and caregivers completed the study. Considerable strain was reported in $46 \%$ and $43 \%$ of the caregivers at the $3^{\text {rd }}$ and $6^{\text {th }}$ month, respectively. Patient factors such as severe disabilities (Barthel Index $\leqq 60$ ), poor cognition (Mini-Mental State Examination $\leqq 23$ ), depression (Beck Depression Inventory $[\mathrm{BDI}] \geqq 10$ ), and recurrent stroke were predictors for caregiver strain. Caregiver factors, such as changed employment status, help from formal caregivers, and depression (BDI $\geqq 10$ ) were also associated with considerable caregiver strain.

Conclusions: Nearly $50 \%$ of caregivers experienced considerable strain. Interventions aimed at reducing the caregivers' strain should focus on enhancing the functional and emotional status of stroke subjects, prevention of recurrent stroke, and efficient management of depression symptoms in caregivers. (Chang Gung Med J 2012;35:392-401)

Key words: stroke, informal caregivers, strain

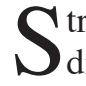
troke is one of the most prevalent causes of adult disability and handicap..$^{(1-4)}$ A substantial proportion of stroke survivors rely on instrumental and emotional support from informal caregivers after acute hospitalization. ${ }^{(5,6)}$ These caregivers are recognized as "informal caregivers" because they are not paid or trained by statutory bodies. The informal caregiver is usually a spouse, child, child-in-law or

\footnotetext{
From the Department of Rehabilitation; 'Department of Neurology, Kaohsiung Chang Gung Memorial Hospital and Chang Gung University College of Medicine, Kaohsiung, Taiwan; ${ }^{2}$ Biostatistics Center and Graduate Institute of Biostatistics; ${ }^{3}$ Department of Public Health, China Medical University, Taichung, Taiwan.

Received: Nov. 30, 2011; Accepted: Feb. 13, 2012

Correspondence to: Dr. Ku-Chou Chang, Department of Neurology, Kaohsiung Chang Gung Memorial Hospital. No. 123, Dapi Rd., Niaosong Dist., Kaohsiung City 833, Taiwan (R.O.C.) Tel: 886-7-7317123 ext. 2283; Fax: 886-7-7315677;

E-mail: kcchang@cgmh.org.tw
} 
close friend of the person in need of care.

Informal caregivers may be central to the process of poststroke care, ${ }^{(6,7)}$ and in determining long-term outcomes for stroke patients. ${ }^{(6,8,9)}$ However, many informal caregivers experience stress and emotional distress as a result of taking care of a disabled person, putting them at high risk of developing their own health problems. This threatens both the sustainability of home care and the recovery of stroke subjects. Although physicians and health care professionals are advised to maximize the well-being of both patients and caregivers, ${ }^{(10,11)}$ less attention is paid to caregiver strain compared with patient outcome.

Caregiver strain can be perceived differently depending on the characteristics of both the patients and the caregivers, and of the social service setting. ${ }^{(12-18)}$ In addition, as a consequence of changing coping abilities of the caregivers and functional status of the patients, the impact of caregiving can be different at different times. ${ }^{(12,16,19,20)}$ There is a need for more longitudinal studies under different social settings and healthcare systems to determine the difficulties in caring for stroke patients and to determine predicting factors for caregiving strain.

Empirically, stroke survivors are discharged from care facilities 3 months after the stroke, after which informal caregivers must learn to provide care at home. ${ }^{(21,22)}$ Six months after the stroke may be long enough for informal caregivers to become aware of all the problems that occur in caring for a patient. Thus, data regarding changes in strain experienced by caregivers 3 and 6 months after a stroke might be of value in determining the changing burden of caregivers. Knowledge of this information would help to identify caregivers at risk of strain and to determine workable interventions to improve the quality of care at appropriate times after a stroke. This study aimed to examine changes in strain that are experienced by caregivers at 3 and 6 months after a stroke and to determine factors associated with these changes.

\section{METHODS}

This was a prospective longitudinal study that recruited ischemic stroke patients admitted to a tertiary referral hospital in southern Taiwan. Patients 40 to 80 years old who had suffered from a recent ischemic stroke as confirmed by brain imaging were recruited during acute hospitalization. Patients were medically and neurologically stable at the time of recruitment and were expected to return home. All patients were required to have informal caregivers who were willing and able to provide support after discharge from the hospital.

A study nurse contacted families and patients to explain the study and to seek consent.

An informal caregiver was defined as "an unpaid person who is most closely involved in taking care of stroke survivors, but not necessarily living with the patient." If multiple persons were involved in caregiving, the families or patients were asked to identify one caregiver for interview. The same study nurse interviewed each patient/caregiver pair at clinics 3 and 6 months after the stroke.

At each visit, the neurological deficits of the patients were assessed using the NIH Stroke Scale (NIHSS), with 0-6, 7-15, 16-38 points being stratified as a mild, moderate, and severe stroke, respectively. ${ }^{(21)}$ Disability was evaluated using the Barthel Index (BI), with a $\mathrm{BI} \leq 60$ considered moderate to severe disability, and $>60$ as mild. ${ }^{(21)}$ Global handicap was assessed by the modified Rankin Scale (MRS), with an MRS score $\leq 2$ considered a favorable outcome. ${ }^{(23)}$ Cognitive function was evaluated using the Mini-Mental State Examination (MMSE), with 20 items and a maximum sum score of 30. ${ }^{(24)}$ Cognitive impairment was defined as an MMSE score $\leq 23 .{ }^{(6)}$ Other patient characteristics were also recorded, such as whether this was a first-ever stroke, walking ability, presence of aphasia, incontinence, use of a Foley catheter, tube feeding, and tracheotomy.

Characteristics of the informal caregivers, including educational level, employment status, marital status, self-reported health status, and economic status, were recorded. Current economic status was categorized as $>30,000$ and $\leq 30,000$ NT\$/month. The health status of the caregiver was assessed by self-rated global health on a 3-point Likert scale. Caregivers were asked to report the average number of hours spent helping the patient per day. The use of resources such as formal caregivers (e.g., a foreign or domestic employee who was paid for providing care or a nursing home) or alternative family caregivers who shared caring work with the informal caregiver was also recorded.

Depression in patients and caregivers was assessed using the Beck Depression Inventory (BDI) 
at each visit. ${ }^{(25)}$ We used a BDI score of 10 as the criterion for mild depression. ${ }^{(25)}$ Patients with severe aphasia or cognitive impairments could not be interviewed and were assigned a BDI score of 63 . Caregivers' perceived burden was assessed using the Caregiver Strain Index (CSI). ${ }^{(26)}$ The CSI is a brief and easily administered screening instrument for identification of strain. The 13-item CSI measures common stressors experienced by caregivers. Items are scored yes (1) or no (0) and are summed, with higher scores indicating greater strain. A CSI score $\geq 7$ was considered an indicator of considerable strain. ${ }^{(26)}$

\section{Statistical analysis}

Before performing any hypothesis tests, patient and caregiver characteristics were classed into two groups, one group being time-independent variables (e.g., age and gender) and the other being timedependent variables (e.g., NIHSS, BI, MRS, MMSE, BDI, formal caregivers, family income, and CSI). We compared differences for each time-dependent variable at 2 different time points, i.e., the $3^{\text {rd }}$ and $6^{\text {th }}$ months after stroke, by using McNemar's or Bowker's tests. For univariate analysis, the chisquare or Fisher's exact tests were used to determine whether there were significant differences between the perceived strain of caregivers and the distribution of these characteristics in both patients and caregivers. For our longitudinal dataset, there were repeated measures for 89 pairs of patients and caregivers, and generalized estimating equation (GEE) analysis was performed as the method of multivariable logistic regression analysis. GEEs were used to explore various factors that impacted the odds of the caregivers experiencing considerable strain, and to adjust the influence of confounding factors to reduce type I errors. The backward elimination technique, where we set the criteria of the $p$-value $<0.1$, was introduced for selecting explanatory variables. A $p$ value less than 0.05 was regarded as statistically significant. All analyses were performed using SAS version 9.2 (SAS Institute Inc., Cary, NC, U.S.A.).

\section{RESULTS}

Ninety-eight patients and their caregivers were recruited, with 89 patient/caregiver pairs completing the study. During the study period 2 patients died and
7 patients/caregivers were lost to follow-up, either because of withdrawal of consent or loss of contact. There were 5 patients with severe aphasia and/or cognitive impairments who could not be interviewed and were assessed as BDI $=63$. There were no differences between the group that was lost to followup and the remaining 89 patients/caregivers with respect to age, sex, education, or extent of patient dependence. This report explored the data obtained from the 89 patient/caregiver pairs.

The mean age of the 89 stroke patients was 66.1 years, $54 \%$ were male and $71 \%$ were married. The mean age of the 89 caregivers was 52.3 years, and $47 \%$ were male. Nearly half $(47 \%)$ of the caregivers had education levels greater than 9 years and most were married, with $44 \%$ being spouses of the patient (Table 1).

Except for an increased use of formal caregivers from the $3^{\text {rd }}$ to $6^{\text {th }}$ month after stroke, there were no differences among time-dependent variables (Table 2).

Characteristics of caregivers, patients, and resource use were explored for caregivers who reported considerable strain (Tables 3 and 4). Caregivers tended to have considerable strain when caring for patients with many neurological deficits,

Table 1. Characteristics of 89 Stroke Survivors and Their Informal Caregivers

\begin{tabular}{lrl}
\hline Characteristics & Mean $\left(25^{\text {th }}-75^{\text {th }}\right.$ percentile $)$ or No. $(\%)$ \\
\hline Patients $(\mathrm{N}=89)$ & 66.1 & $(59.0-74.0)$ \\
Age, $\mathrm{y}$ & 48 & $(54)$ \\
Male & 63 & $(71)$ \\
Married & & \\
Caregivers $(\mathrm{N}=89)$ & 52.3 & $(42.0-66.0)$ \\
Age, $\mathrm{y}$ & 42 & $(47)$ \\
Male & 75 & $(84)$ \\
Married & & \\
Education level & 42 & $(47)$ \\
$>9$ years & 35 & $(39)$ \\
$\leq 9$ years & 12 & $(14)$ \\
Illiterate & & \\
Relationship & 39 & $(44)$ \\
Spouse & 29 & $(33)$ \\
Son & 10 & $(11)$ \\
Daughter & 8 & $(9)$ \\
Daughter in law & 3 & $(3)$ \\
Relative /friend & & \\
&
\end{tabular}


Table 2. Time-Dependent Variables at the $3^{\text {rd }}$ and $6^{\text {th }}$ Month after Stroke

\begin{tabular}{|c|c|c|c|}
\hline & $\begin{array}{c}3 \text { months } \\
\text { No. (\%) }\end{array}$ & $\begin{array}{l}6 \text { months } \\
\text { No. }(\%)\end{array}$ & $p$-value* \\
\hline \multicolumn{4}{|l|}{ Patients } \\
\hline First-ever stroke & $63(71)$ & $58(65)$ & 0.063 \\
\hline Aphasia & $16(18)$ & $16(18)$ & 1.000 \\
\hline Urine incontinence & $20(23)$ & $22(25)$ & 0.774 \\
\hline Tube feeding & $14(16)$ & $19(21)$ & 0.125 \\
\hline Tracheostomy & $4(5)$ & $4(5)$ & NA \\
\hline Foley catheter & $5(6)$ & $8(9)$ & 0.375 \\
\hline \multicolumn{4}{|l|}{ NIHSS } \\
\hline $0 \leq \mathrm{NIHSS} \leq 6$ & $48(54)$ & $49(55)$ & 0.172 \\
\hline $7 \leq \mathrm{NIHSS} \leq 15$ & $26(29)$ & $23(26)$ & \\
\hline $16 \leq \mathrm{NIHSS} \leq 38$ & 15 (17) & 17 (19) & \\
\hline \multicolumn{4}{|l|}{$\mathrm{BI}$} \\
\hline $\mathrm{BI} \leq 60$ & 42 (47) & $38(43)$ & 0.289 \\
\hline \multicolumn{4}{|l|}{ MRS } \\
\hline MRS $>2$ & $43(48)$ & $42(47)$ & 1.000 \\
\hline \multicolumn{4}{|l|}{ MMSE } \\
\hline MMSE $\leq 23$ & $51(57)$ & $47(53)$ & 0.344 \\
\hline \multicolumn{4}{|l|}{ BDI } \\
\hline $\mathrm{BDI} \geq 10$ & $52(58)$ & 51 & 1.000 \\
\hline \multicolumn{4}{|l|}{ Caregivers } \\
\hline \multicolumn{4}{|l|}{ Health status } \\
\hline Good & $43(48)$ & $50(56)$ & 0.172 \\
\hline Fair & $33(37)$ & $25(28)$ & \\
\hline Poor & $13(15)$ & $14(16)$ & \\
\hline Employed & $49(55)$ & $43(48)$ & 0.146 \\
\hline Time helping $\leq 3$ hours/d & $37(42)$ & $37(42)$ & 1.000 \\
\hline \multicolumn{4}{|l|}{ BDI } \\
\hline $\mathrm{BDI} \geq 10$ & 17 (19) & $18(20)$ & 1.000 \\
\hline Alternative caregivers & $51(57)$ & $46(52)$ & 0.302 \\
\hline Formal caregivers & $19(21)$ & $26(29)$ & 0.016 \\
\hline Family income $>30,000$ & $57(64)$ & $56(63)$ & 1.000 \\
\hline \multicolumn{4}{|l|}{ CSI } \\
\hline $\mathrm{CSI} \geq 7$ & $41(46)$ & $38(43)$ & 0.629 \\
\hline
\end{tabular}

Abbreviations: NIHSS: NIH stroke score; BI: Barthel Index; MRS: modified Rankin Scale; MMSE: Mini-Mental State Examination; BDI: Beck Depression Inventory; CSI: Caregiver Strain index; *: Using McNemar's test for paired $2 \times 2$ table and Bowker's test for paired $3 \times 3$ table; NA: There are no discordant pairs. Income is given in New Taiwan dollars/ month. severe disability, cognitive impairment, and depression. Caregivers also tended to have considerable strain if they were depressed, had poor health, were unemployed, were changing employment status, or were spending more than 3 hours a day caring for patients. Caregivers had considerable strain even when receiving help from formal caregivers.

Severe patient disability, poor cognition, depression, recurrent stroke, changes in caregiver employment status, use of formal caregivers, and depression were all independent predictors of considerable strain in caregivers (Table 5).

\section{DISCUSSION}

This study highlights the common and persistent strain experienced by informal caregivers of stroke subjects. Increased caregiver strain was predicted by patients with severe disabilities, poor cognition, depression, and recurrent stroke, and by caregivers who changed employment status, received help from formal caregivers, and experienced depression.

In our study $46 \%$ and $43 \%$ of caregivers had considerable strain 3 and 6 months, respectively. after a stroke. This finding is in line with previous studies which have reported that $28 \%$ to $44 \%$ of stroke caregivers experience considerable strain 3 to 6 months after a stroke. ${ }^{(16-20)}$ Race and culture may contribute to the perception of caregiver burden. While it has been generally assumed that Asian caregivers might have more social networking than caregivers in Western countries, the rate of considerable strain among caregivers in the current study was not found to be less than that in previous studies in other countries. This issue warrants further exploration.

As high NIHSS, low BI, and poor MRS scores were associated with considerable strain in caregivers at 3 and 6 months post stroke, our results support the obvious relationship between caregiver strain and stroke severity. ${ }^{(13,15,16,18,20,27,28)}$ Since a low BI was an independent predictor of considerable caregiver strain $(\mathrm{BI}<60)$, strategies that deal with stroke-related disability might alleviate the burden of caregivers. We found that urine incontinence, tube feedings, and a tracheostomy in patients were also associated with considerable strain in their caregivers at each time point. Language impairment and insertion of a Foley catheter were additional associated factors at the $3^{\text {rd }}$ month. Helping caregivers manage 
Table 3. Caregiver Strain Associated with Characteristics of Patients

\begin{tabular}{|c|c|c|c|c|c|c|}
\hline \multirow[b]{2}{*}{ Patients } & \multicolumn{3}{|c|}{3 months } & \multicolumn{3}{|c|}{6 months } \\
\hline & $\begin{array}{l}\text { CSI < } \\
(n=48)\end{array}$ & $\begin{array}{l}\mathrm{CSI} \geq 7 \\
(\mathrm{n}=41)\end{array}$ & $p$-value* & $\begin{array}{l}\text { CSI }<7 \\
(\mathrm{n}=51)\end{array}$ & $\begin{array}{l}\mathrm{CSI} \geq 7 \\
(\mathrm{n}=38)\end{array}$ & $p$-value* \\
\hline Age & & & 0.517 & & & 0.162 \\
\hline$<65$ & $22(58)$ & $16(42)$ & & $25(66)$ & $13(34)$ & \\
\hline$\geq 65$ & $26(51)$ & $25(49)$ & & $26(51)$ & $25(49)$ & \\
\hline Sex & & & 0.962 & & & 0.281 \\
\hline Male & $26(54)$ & $22(46)$ & & $25(52)$ & $23(48)$ & \\
\hline Female & $22(54)$ & $19(46)$ & & $26(63)$ & $15(37)$ & \\
\hline First-ever stroke & & & 0.005 & & & 0.010 \\
\hline Yes & $40(63)$ & $23(37)$ & & $39(67)$ & $19(33)$ & \\
\hline No & $8(31)$ & $18(69)$ & & $12(39)$ & $19(61)$ & \\
\hline Aphasia & & & 0.044 & & & 0.077 \\
\hline Yes & $5(31)$ & $11(69)$ & & $6(37)$ & $10(63)$ & \\
\hline No & $43(59)$ & $30(41)$ & & $45(62)$ & $28(38)$ & \\
\hline Urine incontinence & & & 0.003 & & & $<0.001$ \\
\hline Yes & $5(25)$ & $15(75)$ & & $5(23)$ & $17(77)$ & \\
\hline No & $43(62)$ & $26(38)$ & & $46(69)$ & $21(31)$ & \\
\hline Tube feeding & & & 0.008 & & & 0.002 \\
\hline Yes & $3(21)$ & $11(79)$ & & $5(26)$ & $14(74)$ & \\
\hline No & $45(60)$ & $30(40)$ & & $46(66)$ & $24(34)$ & \\
\hline Tracheostomy & & & $0.042^{+}$ & & & $0.030^{+}$ \\
\hline Yes & $0(0)$ & $4(100)$ & & $0(0)$ & $4(100)$ & \\
\hline No & $48(56)$ & $37(44)$ & & $51(60)$ & $34(40)$ & \\
\hline Foley catheter & & & $0.018^{\dagger}$ & & & $0.069^{\dagger}$ \\
\hline Yes & $0(0) 0$ & $5(100)$ & & $2(25)$ & $6(75)$ & \\
\hline No & $48(57)$ & $36(43)$ & & $49(60)$ & $32(40)$ & \\
\hline \multicolumn{7}{|c|}{ Clinical characteristics } \\
\hline NIHSS & & & $<0.001$ & & & $<0.001$ \\
\hline $0-6$ & $38(79)$ & $10(21)$ & & $38(78)$ & $11(22)$ & \\
\hline $7-15$ & $8(31)$ & $18(69)$ & & $12(52)$ & $11(48)$ & \\
\hline $16-38$ & $2(13)$ & $13(87)$ & & $1(6)$ & $16(94)$ & \\
\hline BI & & & $<0.001$ & & & $<0.001$ \\
\hline$\leq 60$ & $10(24)$ & $32(76)$ & & $11(29)$ & $27(71)$ & \\
\hline$>60$ & $38(81)$ & $9(19)$ & & $40(78)$ & $11(22)$ & \\
\hline MRS & & & $<0.001$ & & & $<0.001$ \\
\hline$\leq 2$ & $38(83)$ & $8(17)$ & & $38(81)$ & $9(19)$ & \\
\hline$>2$ & $10(23)$ & $33(77)$ & & $13(31)$ & $29(69)$ & \\
\hline MMSE & & & $<0.001$ & & & $<0.001$ \\
\hline$\leq 23$ & $17(33)$ & $34(67)$ & & $17(36)$ & $30(64)$ & \\
\hline$>23$ & $31(82)$ & $7(18)$ & & $34(81)$ & $8(19)$ & \\
\hline BDI & & & $<0.001$ & & & 0.067 \\
\hline$<10$ & $29(78)$ & $8(22)$ & & $26(68)$ & $12(32)$ & \\
\hline$\geq 10$ & $19(37)$ & $33(63)$ & & 25 (49) & $26(51)$ & \\
\hline
\end{tabular}

Abbreviations: CSI: Caregiver Strain index; NIHSS: NIH stroke score; BI: Barthel Index; MRS: modified Rankin Scale; MMSE: MiniMental State Examination; BDI: Beck Depression Inventory; *: Chi-square test; $†$ : Fisher's exact test. 
Table 4. Caregiver Strain Associated with Characteristics of Caregivers

\begin{tabular}{|c|c|c|c|c|c|c|}
\hline \multirow[b]{2}{*}{ Caregivers } & \multicolumn{3}{|c|}{3 months } & \multicolumn{3}{|c|}{6 months } \\
\hline & $\begin{array}{l}\text { CSI < } 7 \\
(n=48)\end{array}$ & $\begin{array}{l}\mathrm{CSI} \geq 7 \\
(\mathrm{n}=41)\end{array}$ & $p$-value* & $\begin{array}{l}\text { CSI < } \\
(\mathrm{n}=51)\end{array}$ & $\begin{array}{l}\mathrm{CSI} \geq 7 \\
(\mathrm{n}=38)\end{array}$ & $p$-value* \\
\hline$\overline{\text { Age }}$ & & & 0.259 & & & 0.476 \\
\hline$<65$ & $31(50)$ & $31(50)$ & & $34(55)$ & $28(45)$ & \\
\hline$\geq 65$ & $17(63)$ & $10(37)$ & & $17(63)$ & $10(37)$ & \\
\hline Sex & & & 0.064 & & & 0.208 \\
\hline Male & $27(64)$ & $15(36)$ & & $27(64)$ & $15(36)$ & \\
\hline Female & $21(45)$ & $26(55)$ & & $24(51)$ & $23(49)$ & \\
\hline Health status & & & 0.210 & & & 0.006 \\
\hline Good & $27(63)$ & $16(37)$ & & $36(72)$ & $14(28)$ & \\
\hline Fair & $14(42)$ & $19(58)$ & & $9(36)$ & $16(64)$ & \\
\hline Poor & $7(54)$ & $6(46)$ & & $6(43)$ & $8(57)$ & \\
\hline Relationship & & & $0.155^{\dagger}$ & & & $0.631^{\dagger}$ \\
\hline Spouse & $23(59)$ & $16(41)$ & & $24(62)$ & $15(38)$ & \\
\hline Children/daughter in law & $25(53)$ & $22(47)$ & & $26(55)$ & $21(45)$ & \\
\hline Others & $0(0)$ & $3(100)$ & & $1(33)$ & $2(67)$ & \\
\hline Education level (years) & & & 0.566 & & & 0.375 \\
\hline$\leq 9$ & $24(51)$ & $23(49)$ & & $29(62)$ & $18(38)$ & \\
\hline$>9$ & $24(57)$ & $18(43)$ & & $22(52)$ & $20(48)$ & \\
\hline Married & & & 0.365 & & & 0.989 \\
\hline Yes & $42(56)$ & $33(44)$ & & $43(57)$ & $32(43)$ & \\
\hline No & $6(43)$ & $8(57)$ & & $8(57)$ & $6(43)$ & \\
\hline Employed & & & 0.127 & & & 0.022 \\
\hline Yes & $30(61)$ & $19(39)$ & & $30(70)$ & $13(30)$ & \\
\hline No & $18(45)$ & $22(55)$ & & $21(46)$ & $25(54)$ & \\
\hline Change in employment status & & & 0.241 & & & 0.001 \\
\hline Yes & $2(29)$ & $5(71)$ & & $2(15)$ & $11(85)$ & \\
\hline No & $46(56)$ & $36(44)$ & & $49(64)$ & $27(36)$ & \\
\hline Income & & & 0.317 & & & 0.197 \\
\hline$\leq 30,000$ & $15(47)$ & $17(53)$ & & $16(48)$ & $17(52)$ & \\
\hline$>30,000$ & $33(58)$ & $24(42)$ & & $35(63)$ & $21(37)$ & \\
\hline Time help (hours) & & & 0.081 & & & 0.037 \\
\hline$\leq 3$ & $24(65)$ & $13(35)$ & & $26(70)$ & $11(30)$ & \\
\hline$>3$ & $24(46)$ & $28(54)$ & & $25(48)$ & $27(52)$ & \\
\hline BDI & & & 0.024 & & & 0.001 \\
\hline$<10$ & $43(60)$ & $29(40)$ & & $47(66)$ & $24(34)$ & \\
\hline$\geq 10$ & $5(29)$ & $12(71)$ & & $4(22)$ & $14(78)$ & \\
\hline \multicolumn{7}{|l|}{ Resource use } \\
\hline Alternative caregivers & & & 0.517 & & & 0.150 \\
\hline Yes & $26(51)$ & $25(49)$ & & $23(50)$ & $23(50)$ & \\
\hline No & $22(58)$ & $16(42)$ & & $28(65)$ & $15(35)$ & \\
\hline Formal caregivers & & & 0.244 & & & 0.021 \\
\hline Yes & $8(42)$ & $11(58)$ & & $10(38)$ & $16(62)$ & \\
\hline No & $40(57)$ & $30(43)$ & & $41(65)$ & $22(35)$ & \\
\hline Out- patient rehabilitation & & & 0.457 & & & 0.930 \\
\hline Yes & $14(48)$ & $15(52)$ & & $13(57)$ & $10(43)$ & \\
\hline No & $34(57)$ & $26(43)$ & & $38(58)$ & $28(42)$ & \\
\hline
\end{tabular}

Abbreviations: CSI: Caregiver Strain index; BDI: Beck Depression Inventory; *: Chi-square test; $\uparrow$ : Fisher's exact test. Income is given in New Taiwan dollars/ month: Formal caregivers, includes foreign employees, domestic employees, and nursing homes. 
Table 5. Results of Caregiver Considerable Strain Rate for Correlated Data Using GEE

\begin{tabular}{lrrr}
\hline & \multicolumn{4}{c}{ CSI $\geq 7$} \\
\cline { 2 - 4 } Variables & $\begin{array}{c}\text { Odds } \\
\text { ratio }\end{array}$ & $(95 \%$ CI $)$ & $p$ value \\
& 1 & & \\
Time points (3 months as reference) & 0.89 & $(0.44,1.81)$ & 0.749 \\
$\quad 6$ months & & & \\
Patient characteristics & 1 & & \\
BI $(>60$ as reference) & 12.22 & $(3.89,38.39)$ & $<0.001$ \\
$\quad \leq 60$ & 1 & & \\
MMSE $(>23$ as reference) & 5.53 & $(1.85,16.51)$ & 0.002 \\
$\quad \leq 23$ & 1 & & \\
BDI $(<10$ as reference) & 3.32 & $(1.21,9.11)$ & 0.020 \\
$\quad \geq 10$ & 1 & & \\
First-ever stroke (Yes as reference) & 2.83 & $(1.18,6.81)$ & 0.020 \\
$\quad$ No & & & \\
Caregiver & 1 & & \\
Change in employment status (No as reference) & 8.96 & $(1.88,42.75)$ & 0.006 \\
$\quad$ Yes & 1 & & \\
Formal caregiver (No as reference) & 6.85 & $(1.91,24.52)$ & 0.003 \\
$\quad$ Yes & 1 & & \\
BDI $(<10$ as reference) & 3.19 & $(1.04,9.75)$ & 0.042 \\
$\quad \geq 10$ & & & \\
\hline
\end{tabular}

Abbreviations: GEE: Generalized Estimating Equations; CSI: Caregiver Strain index; BI: Barthel Index; MMSE: Mini-Mental State Examination; BDI: Beck Depression Inventory.

problems, such as sphincter control, feeding, and communication with patients, should be a part of rehabilitation programs.

Our findings suggest that carers of first-ever stroke subjects may have different experiences than those caring for patients with a recurrent stroke. From our study, care of recurrent stroke patients was more likely to cause considerable strain than care of first-ever stroke patients. A recurrent stroke usually results in deterioration of functional status, which increases the difficulty of care. Moreover, informal caregivers may worry about another recurrent stroke in the future. Thus, we should not assume that caregivers will adjust more easily to their role if they have had previous experience.

Emotional disorders and cognitive impairments in stroke subjects have a negative influence on their caregivers. ${ }^{(14,15,19,28-32)}$ We found that both depression and cognitive impairment in stroke patients were associated with considerable strain in their caregivers. Thus, interventions that focus on enhancing clinical management of depression and impaired cognition in stroke patients may be helpful in reducing caregiver strain.

In our study, caregivers who changed their employment status during the caregiving period were more likely to experience considerable strain. Seven caregivers had changed their employment status to unemployed at 3 months, and an additional 6 caregivers did so after 6 months. It is possible that changes in employment status caused more strain for caregivers as a consequence of increased financial stress.

A high number of hours of care of a stroke patient per day has been suggested to be related to the burden perceived by caregivers. ${ }^{(13,16,33,34)}$ In our study, more than 3 hours of care daily was associated with increased strain to the caregiver at 6 months. However, this was not found to be an independent predictor via GEE analysis. In addition, the expectation that resource use would have a positive impact on caregiver strain was not supported in this study. We found that neither the presence of an alternative caregiver nor the use of outpatient rehabilitation were associated with decreased caregiver strain. Furthermore, we found that informal caregivers who received help from formal caregivers experienced increased strain..$^{(16,18,28)}$ These results raise 2 issues. First, it is possible that patients with more severe strokes were more likely to need alternative caregiver services. Second, although support services may lessen some of the physical aspects of caregiver strain, they may also induce new problems, such as increased financial stress. This might explain why service input was not necessarily associated with decreased caregiver strain. Further study is needed to clarify this issue.

There were some limitations in this study. It should be noted that the findings of this study could be affected by the selection of patients, all of whom had been hospitalized. Admitted patients are more likely to have suffered a severe stroke, and a community-based study may have revealed lower levels of strain in caregivers. In addition, the sample size for this study was relatively small and the patients recruited were those still alive 3 months after the stroke. With this in mind, the results of this study and the perceptions of the caregivers involved may not be broadly applicable, and factors such as the location and type of services available for stroke patients were not taken into account in this study. 


\section{Conclusion}

Caregivers experienced strain at 3 and 6 months after stroke. Our results indicate the need for interventions to help with adaptation to the role of caregiver and relief of the strain involved. Identifying caregivers who experience considerable strain should be the first step in intervention. Our study offers information on cause and effect relationships between caregivers, care recipients (i.e., stroke survivors), and their environment. Caregiver strain was associated with the function and emotional status of stroke subjects, recurrent stroke, and depression symptoms in caregivers; formal caregivers did not reduce the strain of informal caregivers. Interventions or providing services for stroke subjects should consider the above factors to empower informal caregivers in fulfillment of their role.

\section{Acknowledgement}

This study was conducted with a grant from Chang Gung Memorial Hospital, Kaohsiung, Taiwan CMRPG84017.

\section{REFERENCES}

1. Seale C, Davies P. Outcome measurement in stroke rehabilitation research. Int Disabil Stud 1987;9:155-60.

2. Boult C, Kane RL, Louis TA, Boult L, McCaffrey D. Chronic conditions that lead to functional limitation in the elderly. J Gerontol 1994;49:M28-36.

3. Picavet HS, van den Bos GA. The contribution of six chronic conditions to the total burden of mobility disability in the dutch population. Am J Public Health 1997;87: 1680-2.

4. Stineman MG, Maislin G, Fiedler RC, Granger CV. A prediction model for functional recovery in stroke. Stroke 1997;28:550-6.

5. Han B, Haley WE. Family caregiving for patients with stroke. Review and analysis. Stroke 1999;30:1478-85.

6. Anderson CS, Linto J, Stewart-Wynne EG. A populationbased assessment of the impact and burden of caregiving for long-term stroke survivors. Stroke 1995;26:843-9.

7. Wade DT, Legh-Smith J, Hewer RL. Effects of living with and looking after survivors of a stroke. Br Med J (Clin Res Ed) 1986;293:418-20.

8. Evans RL, Connis RT, Bishop DS, Hendricks RD, Haselkorn JK. Stroke: A family dilemma. Disabil Rehabil 1994;16:110-8.

9. Glass TA, Matchar DB, Belyea M, Feussner JR. Impact of social support on outcome in first stroke. Stroke 1993;24: 64-70.
10. Boult C, Brummel-Smith K. Post-stroke rehabilitation guidelines. The Clinical Practice Committee of the American Geriatrics Society. J Am Geriatr Soc 1997;45: 881-3.

11. van Heugten C, Visser-Meily A, Post M, Lindeman E. Care for carers of stroke patients: evidence-based clinical practice guidelines. J Rehabil Med 2006;38:153-8.

12. Berg A, Palomaki H, Lonnqvist J, Lehtihalmes M, Kaste M. Depression among caregivers of stroke survivors. Stroke 2005;36:639-43.

13. Choi-Kwon S, Kim HS, Kwon SU, Kim JS. Factors affecting the burden on caregivers of stroke survivors in South Korea. Arch Phys Med Rehabil 2005;86:1043-8.

14. Smith LN, Norrie J, Kerr SM, Lawrence IM, Langhorne $\mathrm{P}$, Lees KR. Impact and influences on caregiver outcomes at one year post-stroke. Cerebrovasc Dis 2004;18:145-53.

15. Blake H, Lincoln NB. Factors associated with strain in co-resident spouses of patients following stroke. Clin Rehabil 2000;14:307-14.

16. Bugge C, Alexander H, Hagen S. Stroke patients' informal caregivers. Patient, caregiver, and service factors that affect caregiver strain. Stroke 1999;30:1517-23.

17. van Exel NJ, Koopmanschap MA, van den Berg B, Brouwer WB, van den Bos GA. Burden of informal caregiving for stroke patients. Identification of caregivers at risk of adverse health effects. Cerebrovasc Dis 2005;19: $11-7$.

18. Ilse IB, Feys H, de Wit L, Putman K, de Weerdt W. Stroke caregivers' strain: Prevalence and determinants in the first six months after stroke. Disabil Rehabil 2008;30:523-30.

19. Tooth L, McKenna K, Barnett A, Prescott C, Murphy S. Caregiver burden, time spent caring and health status in the first 12 months following stroke. Brain Inj 2005;19: 963-74.

20. Blake H, Lincoln NB, Clarke DD. Caregiver strain in spouses of stroke patients. Clin Rehabil 2003;17:312-7.

21. Chang KC, Tseng MC, Weng HH, Lin YH, Liou CW, Tan TY. Prediction of length of stay of first-ever ischemic stroke. Stroke 2002;33:2670-4.

22. Tseng MC, Chang KC. Stroke severity and early recovery after first-ever ischemic stroke: Results of a hospitalbased study in Taiwan. Health Policy 2006;79:73-8.

23. de Haan R, Limburg M, Bossuyt P, van der Meulen J, Aaronson N. The clinical meaning of Rankin 'handicap' grades after stroke. Stroke 1995;26:2027-30.

24. Folstein MF, Folstein SE, McHugh PR. "Mini-mental state". A practical method for grading the cognitive state of patients for the clinician. J Psychiatr Res 1975;12:18998.

25. Kendall PC, Hollon SD, Beck AT, Hammen CL, Ingram RE. Issues and recommendations regarding use of the Beck Depression Inventory. Cogn Ther Res 1987;11:28999.

26. Robinson BC. Validation of a caregiver strain index. J Gerontol 1983;38:344-8. 
27. Scholte op Reimer WJ, de Haan RJ, Rijnders PT, Limburg $\mathrm{M}$, van den Bos GA. The burden of caregiving in partners of long-term stroke survivors. Stroke 1998;29:1605-11.

28. McCullagh E, Brigstocke G, Donaldson N, Kalra L. Determinants of caregiving burden and quality of life in caregivers of stroke patients. Stroke 2005;36:2181-6.

29. van den Heuvel ET, de Witte LP, Schure LM, Sanderman $\mathrm{R}$, Meyboom-de Jong B. Risk factors for burn-out in caregivers of stroke patients, and possibilities for intervention. Clin Rehabil 2001;15:669-77.

30. Thommessen B, Wyller TB, Bautz-Holter E, Laake K. Acute phase predictors of subsequent psychosocial burden in carers of elderly stroke patients. Cerebrovasc Dis 2001;11:201-6.
31. Das S, Hazra A, Ray BK, Ghosal M, Banerjee TK, Roy T, Chaudhuri A, Raut DK, Das SK. Burden among stroke caregivers: Results of a community-based study from Kolkata, India. Stroke 2010;41:2965-8.

32. Cameron JI, Cheung AM, Streiner DL, Coyte PC, Stewart DE. Stroke survivor depressive symptoms are associated with family caregiver depression during the first 2 years poststroke. Stroke 2010;42:302-6.

33. Morimoto T, Schreiner AS, Asano H. Caregiver burden and health-related quality of life among Japanese stroke caregivers. Age Ageing 2003;32:218-23.

34. Periard ME, Ames BD. Lifestyle changes and coping patterns among caregivers of stroke survivors. Public Health Nurs 1993;10:252-6. 


\title{
中風病患非正式照顧者之負荷程度及相關因子
}

\author{
洪視雯 黄裕浮 ${ }^{1}$ 陳錦華 ${ }^{2}$ 廖麗娜 ${ }^{3}$ 林純如 卓佳穎 張谷州 $^{1}$
}

背 景：中風是造成成人失能及殘障的最主要原因之一。非正式的主要照顧者是中風後照顧 過程的核心人物。評估中風病人的主要照顧者的負荷程度, 並且找出導致照顧者過 勞的相關因素, 有助於去發現那些照顧者有過勞的危險, 並且可針對這些因素提出 可行的介入方式, 以增進對中風病患的照護品質。這個研究的目的針對照顧中風病 患的非正式的主要照顧者, 在中風病人中風後三個月到六個月其負荷程度的變化, 以及找出過勞照顧者的預測因子。

方 法: 我們邀集因缺血性中風而住院的病患與其非正式的主要照顧者一起加入研究, 他們 將分別在病人中風後第 3 個月與第 6 個月一起接受訪談。我們以照顧者負荷量表 (Caregiver Strain Index) 去評估照顧者的過勞情形，於此量表中得分超過七分將被視 爲照顧者有過勞情形。我們用廣義估計方程式 (generalized estimating equations) 做資 料分析以找出可能與照顧者過勞的相關因子。

結 果：共 89 位中風病人以及其非正式的照顧者完成此研究。研究發現在第 3 個月有 $46 \%$, 而在第 6 個月有 $43 \%$ 的照顧者有過勞的情形。照顧者過勞的預測因素：中風病患有

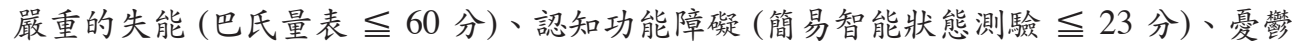

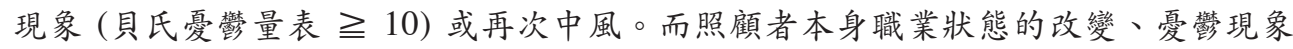
（貝氏憂鐢量表 $\geq 10)$, 或是有正式照顧者協助照顧中風病人, 都與照顧者的過勞因素 有關。

結 論：在中風照護中，有接近一半的非正式主要照顧者發生過勞的狀態。當把介入目標放 在減輕照顧者的工作負荷時, 需著重於改善中風病患的功能與情緒, 預防其再中 風, 並且要處理照顧者的憂橔問題。

(長庚醫誌 2012;35:392-401)

關鍵詞：中風，非正式照顧者，負荷程度

長庚醫療財團法人高雄長庚紀念醫院 復健科, 1神經內科; 長庚大學 醫學院; 1中國醫藥大學 2生物統計研究所 生物統計

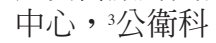

受文日期：民國100年11月30日；接受刊載：民國101年2月13日

通訊作者 : 張谷州醫師, 長庚醫療財團法人高雄長庚紀念醫院 神經內科。高雄市833鳥松區大埤路123號。

Tel: (07)7317123轉2283; Fax: (07)7315677; E-mail: kcchang@cgmh.org.tw 